\title{
Prescription reporting with immediate medication utilization mapping (PRIMUM): development of an alert to improve narcotic prescribing
}

\author{
Rachel B. Seymour ${ }^{1,2^{*}}$, Daniel Leas ${ }^{1,2}$, Meghan K. Wally ${ }^{1,2}$, Joseph R. Hsu ${ }^{1,2}$ and the PRIMUM Group
}

\begin{abstract}
Background: Prescription narcotic overdoses and abuse have reached alarming numbers. To address this epidemic, integrated clinical decision support within the electronic medical record (EMR) to impact prescribing behavior was developed and tested.

Methods: A multidisciplinary Expert Panel identified risk factors for misuse, abuse, or diversion of opioids or benzodiazepines through literature reviews and consensus building for inclusion in a rule within the EMR. We ran the rule "silently" to test the rule and collect baseline data.

Results: Five criteria were programmed to trigger the alert; based on data collected during a "silent" phase, thresholds for triggers were modified. The alert would have fired in $21.75 \%$ of prescribing encounters ( $1.30 \%$ of all encounters; $n=9998$ ), suggesting the alert will have a low prescriber burden yet capture a significant number of at-risk patients.

Conclusions: While the use of the EMR to provide clinical decision support is not new, utilizing it to develop and test an intervention is novel. We successfully built an alert system to address narcotic prescribing by providing critical, objective information at the point of care. The silent phase data were useful to appropriately tune the alert and obtain support for widespread implementation. Future healthcare initiatives can utilize similar methodology to collect data prospectively via the electronic medical record to inform the development, delivery, and evaluation of interventions.
\end{abstract}

Keywords: Opioids, Electronic medical record, Prescription drug abuse, Clinical decision support

Abbreviations: EMR, electronic medical record; PDMP, prescription drug monitoring program; PRIMUM, Prescription Reporting with Immediate Medication Utilization Mapping

\section{Background}

Increases in opioid prescriptions for acute and chronic pain have led to rises in abuse and overdose of prescription narcotics [1]. Unintentional poisonings due to opioid abuse and misuse is an ever growing and significant cause of death and injury. While opioids are the most common class of scheduled medications involved in deaths related to pharmaceutical overdose (75.2 \%), benzodiazepines are involved in nearly a third of these

\footnotetext{
* Correspondence: Rachel.Seymour@carolinashealthcare.org

${ }^{1}$ Department of Orthopaedic Surgery, Carolinas Health Care System, 1000 Blythe Boulevard, Charlotte 28203, NC, USA

${ }^{2}$ Carolinas Trauma Network Research Center of Excellence, Carolinas Health Care System, 1320 Scott Avenue, Charlotte NC 28204, USA
}

overdoses (29.4\%). Additionally, the combination of opioids and benzodiazepines is especially dangerous, with opioids implicated in $77.2 \%$ of deaths involving benzodiazepines, making these two classes of drugs the target of many interventions [2]. Nearly 15,000 people in the United States die from prescription painkiller overdoses every year [3]. In the past 12 years, the rates of unintentional poisoning deaths have surpassed motor vehicle deaths in many states; specifically, unintentional poisoning deaths in North Carolina have risen $308 \%[4,5]$.

All levels of government in the United States recognize the crisis of prescription narcotics. The Executive Office of the President recently released a National Plan for Prescription Drug Abuse, detailing goals relative to this 
problem, including encouraging and even rewarding prescribers who check Prescription Drug Monitoring Programs (PDMP) before writing prescriptions for opioids. The document went further with a call to find ways to utilize the electronic medical record (EMR) to help identify and curb prescription drug abuse [6]. In fact, the 2016 budget includes $\$ 133$ million in new funding to address opioid misuse and abuse, leading the U.S. Health and Human Services Secretary to announce an initiative focusing on three priority areas-prescriber guidelines, naloxone, and medication-assisted treatment-to address the issue [7]. The Centers for Disease Control and Prevention also recognizes the importance of improving opioid prescribing practices as a strategy to reduce the number of people who misuse, abuse, or overdose from these medications [3].

Opioids and benzodiazepines are considered controlled substances according to the U.S. Drug Enforcement Administration, based on the potential for abuse or dependency [8]. Prescribers in the outpatient setting (primary care, internal medicine, and dentists) generate the majority of prescriptions for these controlled substances [9]. In fact, several sources suggest that a small number of these prescribers generate the vast majority of controlled substance prescriptions [10-12]. Therefore, interventions targeting prescribing behavior holds considerable potential for addressing this epidemic. "First do no harm", or Primum non nocere, is a guiding principle in medicine. PRIMUM provides prescribers with critical information to put this principle into practice.

Frequently, prescribers in different care settings are blind to patient interaction with prescribers in other facilities or the critical information that is buried within the overwhelming amount of health information in each patient's electronic record [13, 14]. Multiple attempts to utilize the EMR and institute computerized physician order entry (CPOE) and computer-based clinical decision support have proven successful. Current alert systems programmed into the EMR are designed to make the prescriber aware of critical information. Health maintenance reminders, allergy alerts, prescription drug interaction alerts, and systems to alert physicians to contraindications due to chronic condition or medications are all imbedded in healthcare systems and physician practices [15-19]. Some of these alerts have resulted in behavior change through increased vaccination rates [20], increased use of prophylaxis among patients at risk for deep-vein thrombosis and pulmonary embolism [21], and reduction of prescriptions for contraindicated agents [17], among others. However, the number of alerts have grown to the point where physicians may see 80 alerts per 100 medications ordered, causing these alerts to be ignored in up to $90 \%$ of cases [22], so it is important to spend a significant amount of time developing and testing an alert to maximize its' clinical utility. Research on alert systems indicates that systems focusing on critical information that is clear, concise, and timely is most likely to be well-received and have a positive impact [23-25]. Alert triggers must be optimized to focus on the specific population of interest because alerts that interrupt work flow too often introduce "alert fatigue" and will be ignored [24, 26].

We propose using a technological solution - clinical decision support logic built into the EMR - to help address the problem of unintentional poisonings. Clinical decision support has been developed to increase adherence to clinical practice guidelines for opioid therapy for chronic non-cancer pain in the primary care setting, including dosing recommendations and contraindications $[27,28]$. However, EMR-integrated alert systems have not previously been used to identify patients with evidencebased risk factors for misuse, abuse, or diversion of prescription narcotics, including both opioids and benzodiazepines. Additionally, we believe this is the first attempt to provide decision support in the acute setting.

A multidisciplinary team within our large healthcare system sought to address the prescription narcotic epidemic. The "Prescription Reporting and Immediate Medication Utilization Mapping" intervention, or PRIMUM, is the result of these efforts. We saw an opportunity to utilize the EMR to map prescription utilization and to provide real-time information to prescribers at the point of care, analyze the data on a continuous basis, and make improvements to the system based on feedback from physicians and other prescribers in our numerous care locations, encompassing outpatient clinics, emergency departments, urgent care centers, and hospitals.

The purpose of our investigation was:

1. To create a rule within the EMR to identify at risk patients utilizing searchable, objective indicators of risk for misuse, abuse, and diversion of prescription controlled substances based on peer-reviewed literature and consensus opinion.

2. To use data generated by the rule in an iterative improvement process to tune the timing of the alert and thresholds for the triggers to produce an acceptable number of relevant alerts at the point of care.

\section{Methods}

A multidisciplinary team developed and implemented an alert system that provides integrated clinical decision support into the electronic medical record to impact prescribing behavior and, thereby, reduce prescriptions for opioids and benzodiazepines for at-risk patients to ultimately impact patient outcomes. The development and testing of the rule occurred between December 2014 and May 2015, within our large, integrated healthcare 
system with a common EMR. A list of terms and definitions related to this alert system is provided in Table 1.

\section{Context}

Our healthcare system presents a unique opportunity to test this innovative intervention, with over 40 hospitals, 6 freestanding emergency departments, 28 urgent care locations, and $\sim 800$ physician practices with over 15,000 physicians. A common EMR, Cerner [29], is used by a subset of these facilities, and participated in the implementation of PRIMUM. 15 hospitals, 6 freestanding emergency departments, 27 urgent care locations, and 379 physician practices with over 2500 prescribers were included in the PRIMUM implementation and evaluation. The PRIMUM rule was written into the Cerner EMR using a standard rule template included as part of the EMR program. All of the sites utilizing Cerner were included in all phases of the implementation and testing.

\section{Aim 1}

To create a rule within the EMR to identify at risk patients utilizing searchable, objective indicators of risk for misuse, abuse, and diversion of prescription controlled substances based on peer-reviewed literature and consensus opinion.

\section{Identification of the risk factors}

An Expert Panel of study co-investigators and other key stakeholders, including clinical and research faculty from multiple surgical and medical specialties (Emergency Medicine, Behavioral Health, Orthopaedic Surgery, Internal Medicine, Pharmacy), senior healthcare system physician and administration leadership, Information Services, and experts in the field of unintentional poisoning was convened. Considerable effort was placed on ensuring engagement from physicians, researchers, and all levels of healthcare system administration, including presentations

Table 1 Definitions

\begin{tabular}{ll}
\hline Rule & The rule is executed every time a prescription for an opioid \\
& or benzodiazepine is initiated. The rule is programmed to \\
& search the medical record for the triggers. \\
Trigger & $\begin{array}{l}\text { Triggers are the criteria the rule searches for in the medical } \\
\text { record. These triggers are indicators of risk for opioid or } \\
\text { benzodiazepine misuse, abuse, and/or diversion. }\end{array}$ \\
Alert & $\begin{array}{l}\text { The alert is the pop-up box that appears when the rule } \\
\text { identifies the patient to meet one or more of the trigger } \\
\text { criteria. The alert interrupts workflow and requires the }\end{array}$ \\
& $\begin{array}{l}\text { prescriber to either override the alert and continue with the } \\
\text { prescription or cancel the prescription before proceeding. }\end{array}$ \\
Patient & $\begin{array}{l}\text { A patient encounter is any medical visit or interaction a } \\
\text { patient has with a system provider. This includes inpatient } \\
\text { stays, outpatient visits, lab visits, and ED/Urgent Care visits. }\end{array}$ \\
Prescribing & $\begin{array}{l}\text { Any patient encounter in which a prescriber initiates a } \\
\text { prescription for one or more opioids or benzodiazepines } \\
\text { is defined as a prescribing encounter. }\end{array}$
\end{tabular}

to system-level committees, individual meetings, and grand rounds lectures for physicians across the system. The Expert Panel was charged with selecting criteria that would indicate risk of misuse, abuse, or diversion of prescription narcotics for potential inclusion in a rule built within the EMR. Review of current medical literature was utilized to identify evidence for or against inclusion of these perceived risk factors.

Further extensive literature review conducted by the Expert Panel generated a more expansive list of risk factors associated with misuse, abuse, or diversion of prescription drugs, including demographic characteristics, medical conditions, prescription history and details, and a variety of identified high risk behaviors. A complete listing of all risk factors identified in the peer-reviewed literature is presented in Table 2. Following the systematic review of the literature to outline all potential risk factor, the team worked collaboratively to determine the risk factors to be built into the rule.

\section{Selecting the triggers}

To develop an alert based on these risk factors in the EMR, the criteria must be consistently and accurately documented in the EMR in a specific location that can be searched in an automated fashion. In addition, investigators agreed to focus on objective risk characteristics rather than on subjective or anecdotal assessments of patient risk or behavior in order to limit the potential for the rule introducing bias into the medical encounter. The risk factors were mapped against objective data available and searchable in the EMR to determine which risk factors were initially eligible for inclusion. Demographic characteristics and many comorbidities were excluded as potential triggers as they may indicate risk but have low specificity and, while associated, are not on the causal pathway. Given that many of the documented drugseeking behaviors are more subjective and are not immediately searchable in the EMR, they were not included as triggers. The remaining indicators of risk included prescription details, administration of controlled substances, and information about substance use.

Expert panel discussions of these remaining risk factors yielded 5 categories of objective information available in the EMR that speaks to risk for misuse, abuse, or diversion and that were agreed upon by all members of the panel: current open prescriptions [30-32]; visits to emergency departments or urgent care facilities with onsite treatment with narcotics; 30 day prescription narcotic history [33-35]; history of overdose [36]; and history of positive drug or alcohol screens within the EMR [36-39]. The expert panel came to a consensus on the initial threshold for each trigger based on the literature as well as clinical experience in a variety of specialties with diverse patient populations. 
Table 2 Risk Factors Associated with Misuse, Abuse, or Diversion of Prescription Drugs

\begin{tabular}{|c|c|c|c|}
\hline Demographic characteristics & Medical conditions & Prescription details & High risk behaviors \\
\hline $\begin{array}{l}\text { Race (Caucasian }[37,49-52], \\
\text { Non-Hispanic }[34,37], \\
\text { American Indians/Alaskan } \\
\text { Natives [34]) } \\
\text { High school education or less } \\
{[49,53,54]} \\
\text { Age (Younger to middle aged) } \\
{[34,37,53,55,56]} \\
\text { Not married [37, 50, 53, 54] } \\
\text { Financial Problems [37] } \\
\text { Unemployed [37] } \\
\text { Male [34, 35, 53, 55, 57] } \\
\text { Income extremes [34, 53, 55, 57] } \\
\text { Rural residence [34, 37] } \\
\text { LGBT [57] } \\
\text { Public insurance [55] } \\
\text { Low social class [58] } \\
\text { Family history of substance } \\
\text { abuse [59] } \\
\text { Preadolescent sexual abuse [59] }\end{array}$ & $\begin{array}{l}\text { Past Suicide Attempt [49] } \\
\text { Lifetime Heroin use [49] } \\
\text { Pain [39, 49, 50, 54, 60-62] } \\
\text { Tobacco use [37, 54] } \\
\text { Alcohol use [37-39, 57, 59] } \\
\text { Current illicit drug use } \\
\text { (including marijuana, cocaine, } \\
\text { heroin, methamphetamine, } \\
\text { hallucinogens) [37, 39, 57] } \\
\text { Physical disability [37] } \\
\text { Mental health problems } \\
\text { [34, 39, 50, 59, 61, 63] } \\
\text { Substance abuse disorder } \\
\text { [39, 50, 53, 59] } \\
\text { Hepatitis A, B, C [39] } \\
\text { Past hospitalization [50] } \\
\text { Opioid dependence [50] } \\
\text { Liver disease [50] } \\
\text { Congestive heart failure [50] } \\
\text { Cerebrovascular disease [50] } \\
\text { Chronic pulmonary disease [50] } \\
\text { Diabetes [50] } \\
\text { Hypertension [50] } \\
\text { Cancer [50] } \\
\text { Cardiovascular disease [50] } \\
\text { Obesity [50] } \\
\text { Medical comorbidities [55, 63] } \\
\text { Past care at psychiatric hospital [58] } \\
\text { ADHD [64] }\end{array}$ & $\begin{array}{l}\text { Multiple prescribers } \\
{[30,33,34,52,53,56,59,65]} \\
\text { Multiple pharmacies [30, 31, 33, 34, 56] } \\
\text { High community prescribing rates [34] } \\
\text { Treatment with high daily dose } \\
\text { opioids and short-acting opioids [39,50] } \\
\text { Multiple prescriptions [31, 35, 50,52,56] } \\
\text { Overlapping prescriptions [31] } \\
\text { High maximum prescribed daily morphine } \\
\text { equivalent dose [34, 35, 50, 66, 67] } \\
\text { Preexisting opioid use [62] } \\
\text { Co-prescribing of opioids and } \\
\text { benzodiazepines [34] }\end{array}$ & $\begin{array}{l}\text { Multiple prescribers } \\
{[30,33,34,52,53,56,59,65]} \\
\text { Multiple pharmacies }[30,33,34,56] \\
\text { Multiple ED visits }[50,55,59] \\
\text { Request for refill }[59,60] \\
\text { Lost or stolen medication [59, 60] } \\
\text { Request for parenteral medication [60] } \\
\text { Reported allergies to non-narcotic } \\
\text { medications [52] } \\
\text { Requesting medication by name [52] } \\
\text { Weekend visit [52] } \\
\text { Use of alias [68] } \\
\text { Abnormal urine/blood screen [59] } \\
\text { Resist therapy changes/alternative } \\
\text { therapy [59] } \\
\text { Canceled clinic visits [59] }\end{array}$ \\
\hline
\end{tabular}

\section{Aim 2}

To use data generated by the rule in an iterative improvement process to tune the timing of the alert and thresholds for the triggers to produce an acceptable number of relevant alerts at the point of care.

\section{"Silent" data collection}

We used the EMR rule to prospectively collect surveillance data on narcotic prescriptions (defined as opioids or benzodiazepines) within our health system in a series of defined silent periods. This rule would eventually power the alert in the EMR; however, we were able to run it "silently" (no alert displayed to prescribers) in order to collect data needed to create an effective alert. During the silent phase, the rule captured information about each patient encounter in which an opioid or benzodiazepine was prescribed, including the selected triggers, patient identifiers, location, encounter type, prescriber information, and the medication prescribed.

The first data collection period, Silent Surveillance 1, lasted 1 month and focused on testing the programming of the rule and report generation. We also reviewed preliminary data on risk characteristics and the rate at which the alert would have been triggered. Silent Surveillance 2 was conducted for 1 month to ensure the risk criteria were appropriately tuned and to describe the narcotics prescribing patterns across the system.

\section{Tuning the trigger thresholds}

These triggers were included in a rule developed to retrieve these data from the EMR in real-time and present them to the prescriber at the point of care. In order to assure appropriate tuning of the triggers, we used Silent Surveillance 1 data to revise the triggers to optimize sensitivity and provide meaningful and actionable information to prescribers while minimizing prescriber burden and alert noise [40]. We did not set an a priori alert rate for the triggers. Rather, the panel reviewed the patient populations being captured and missed by the current thresholds and came to a consensus to revise thresholds accordingly. These revised trigger thresholds were monitored during Silent Surveillance 2.

\section{Tuning the timing}

The timing of the alert presentation to the prescriber is critical. The information needs to be presented early enough in the encounter to affect prescribing behavior for the at-risk patients. However, if the alert appears too early in the encounter, it could bias the entire patient visit. Some data suggest that the patient-clinician relationship can affect patient outcome [41], so unnecessary bias of this relationship could cause harm. If the alert appears later in the encounter, after the full prescription has been written, it would improve data capture for the purpose of research, but may contribute to work flow 
disruption within a busy practice or even ignoring the alert since it is after the "point of decision".

In order to determine the appropriate timing of the alert, we conducted literature reviews, expert panel discussions, and individual interviews with practicing clinicians from across the system to obtain feedback. The individual interviews solicited input from clinicians of varying experience (resident and attending), various specialties (emergency medicine, primary care, surgical subspecialties, etc.) and clinician type (physician and nurse practitioner).

\section{Results}

\section{Development of the alert}

The following alert triggers were initially programmed into the rule through the literature search and the expert panel discussions:

- Current prescription with $>30 \%$ remaining expected/ early refill (e.g. A prescription written for 10 days duration was prescribed at least 3 days ago).

-3+ visits to ED or Urgent Care with onsite treatment with opioids (not including visits leading to admission) within previous 30 days.

- 3+ prescriptions for opioids or benzodiazepines within previous 30 days.

- Previous presentation for overdose within the EMR.

- Positive screen for blood alcohol, cocaine, or marijuana within the EMR.
If one or more of the alert triggers are met, once live, an alert fires in the EMR and presents the information to the prescriber (Fig. 1). The alert is concise, clear, and shows details regarding only the triggers that are applicable to that patient [40]. Navigating the alert requires minimal time; the prescriber choses to continue with the prescription as planned or to cancel the prescription.

\section{Tuning the timing and trigger thresholds}

Peer-reviewed literature, consensus panel and individual clinician interviews arrived at placing the alert at the point when the prescriber chooses an opioid or benzodiazepine. This timing was chosen to provide the information as soon as possible and decrease interruption to workflow that would occur if the prescriber received the alert after completing the prescription entirely (i.e. after completing dosage and pill count information or signing the prescription). However, the alert does not appear as soon as the patient record is opened, to avoid labeling patients in encounters where narcotics or benzodiazepines are not involved. The feedback from the expert panel and the clinician interviews was consistent with timing from human factors research on the electronic medical record and avoidance of a negative bias on the encounter [42-45].

After reviewing Silent Surveillance 1 data, the thresholds of two of the triggers were modified (indicated in bold). The initial "current prescription with $>30 \%$ remaining/ early refill" trigger was present in approximately $17 \%$ of prescriptions. Upon further review of the patients meeting

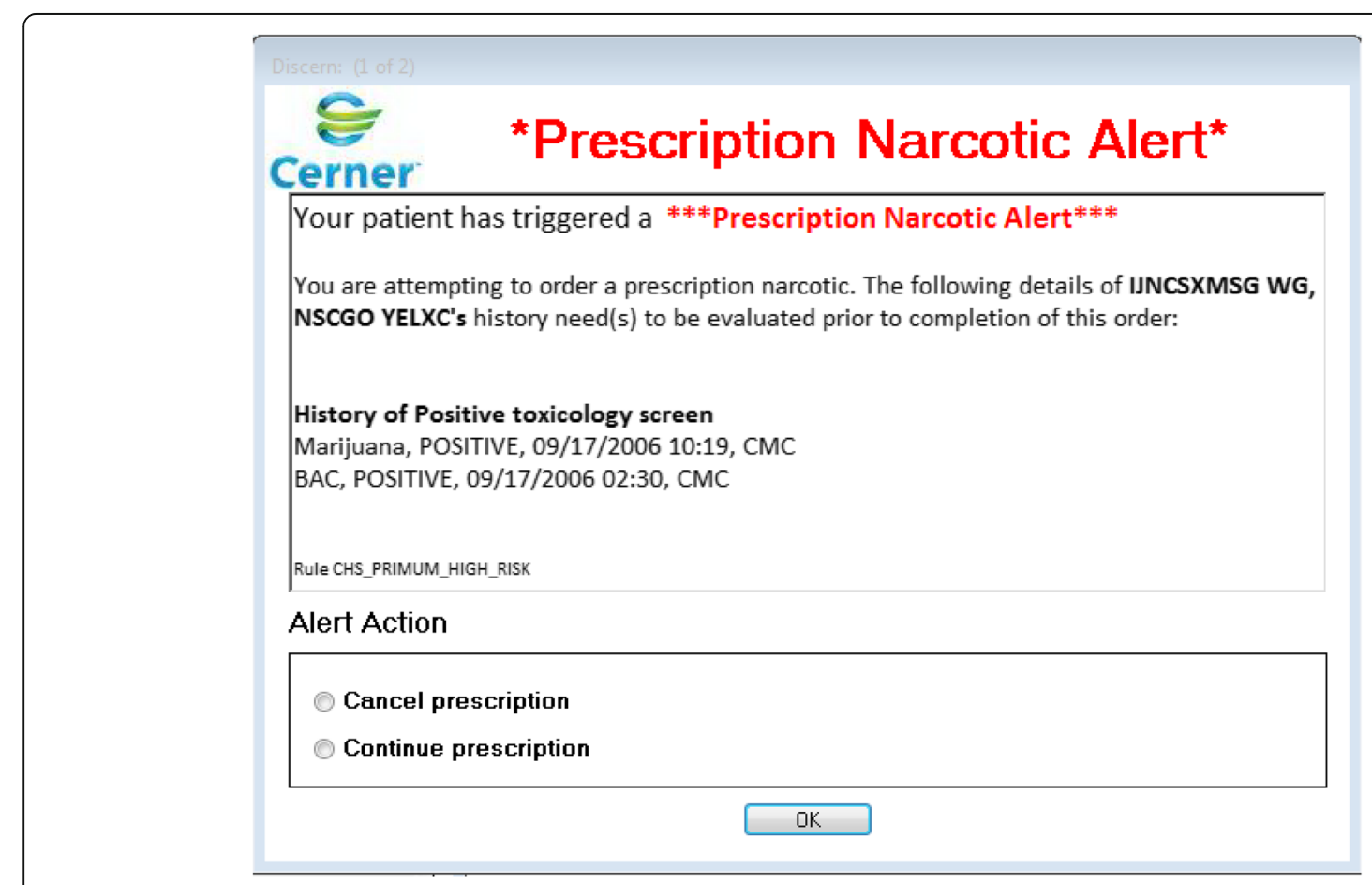

Fig. 1 Prescription Narcotic Alert in the EMR 
this criteria, many of the early refills were found to be in primary care offices. Many patients obtain prescriptions for refills when at a regularly scheduled appointment with their physician and, therefore, the initial threshold of $30 \%$ was believed to be too low to appropriately capture the at risk patient. Conversely, the initial " $3+$ visits to ED or Urgent Care with onsite treatment" trigger was present in only $1.58 \%$ of prescriptions. We determined this rate was low, and we had the potential to identify a greater number of at risk patients without burdening prescribers with high alert rates. The Final Triggers programmed into the rule were:

- Current prescription with $>50 \%$ remaining expected/ early refill.

- 2+ visits to ED or Urgent Care with onsite treatment with opioids (not including visits leading to admission) within previous 30 days.

- 3+ prescriptions for opioids or benzodiazepines within previous 30 days.

- Previous presentation for overdose within the EMR.

- Positive screen for blood alcohol, cocaine, or marijuana within the EMR.

After revision of the trigger thresholds, Silent Surveillance 2 was conducted, and the rates of alerts and triggers were reviewed (Table 3). By changing the threshold to current prescription with $>50 \%$ remaining, the rate of this trigger decreased from $17 \%$ in Silent Surveillance 1 to $13.54 \%$ in Silent Surveillance 2. Decreasing the onsite treatment with narcotics to $2+$ visits in the previous 30 days yielded a rate of $1.96 \%$ instead of $1.58 \%$. Although this change did not increase the rate drastically, the modified alert trigger allowed us to identify over 200 additional patients at risk. These new trigger thresholds were considered appropriately tuned to both identify at risk patients and balance concerns about alert fatigue among prescribers. There were a total of 81,841 prescriptions written during this month in 61,747 prescribing encounters.

The rates of alerts system-wide and by facility type (inpatient, ED/Urgent Care, and outpatient) are presented in Fig. 2. A total of 9998 alerts would have been generated during the month of data collection if the alert were not in "silent" phase. Overall, once live, the alert would have fired in $5.97 \%$ of encounters where a prescription for an opioid or benzodiazepine was written and in only $1.30 \%$ of all face-to-face patient encounters. Alerts would have fired most frequently at inpatient discharges $(8.53 \%$ of total discharges) and least frequently in the outpatient setting $(0.93 \%$ of patient encounters). These rates indicate the alert will have a low burden on prescribers, yet suggest that they will capture a significant number of at-risk patients, yielding substantial public health impact.
Table 3 Characteristics of Controlled Substance Prescribing Encounters, Silent Surveillance 2 ( $n=61,747$ prescribing encounters)

\begin{tabular}{ll}
\hline Characteristic & No. (\% Prescribing encounters) \\
\hline Age of patient & $1552(2.51 \%)$ \\
$<18$ & $45,571(73.80 \%)$ \\
$18-64$ & $14,624(23.68 \%)$ \\
65 & \\
Facility type & $18,267(29.58 \%)$ \\
ED/Urgent Care & $4656(7.54 \%)$ \\
Inpatient Discharge & $38,310(62.04 \%)$ \\
Outpatient including phone calls & $514(0.83 \%)$ \\
Other & \\
Class of drug & $45,165(73.15 \%)$ \\
Opiate & $14,268(23.11 \%)$ \\
Benzodiazepine & $2314(3.75 \%)$ \\
Both & \\
Number of criteria met (of any combination) & \\
0 & $48,164(78.00 \%)$ \\
1 & $10,517(17.03 \%)$ \\
2 & $2654(4.30 \%)$ \\
3 & $369(0.60 \%)$ \\
4 & $43(0.07 \%)$ \\
Priteria met & $0(0.00 \%)$ \\
Prescription with $>50 \%$ remaining & \\
\hline & \\
\hline &
\end{tabular}

\section{Prescription utilization mapping}

The characteristics of prescribing encounters from Silent Surveillance 2 are presented in Table 3. The volume of prescriptions varies by location, with the majority of prescribing encounters occurring in outpatient facilities (62\%). However, the distribution of prescribing encounters among facility types does not match the distribution of overall patient encounters. As expected, inpatient discharges and ED/Urgent Care encounters have disproportionately higher rates of opioid and benzodiazepine prescriptions compared to the number of patient encounters. While inpatient discharges make up less than $2 \%$ of encounters, they represent $7.5 \%$ of prescribing encounters. Similarly, ED/Urgent Care encounters represent less than 


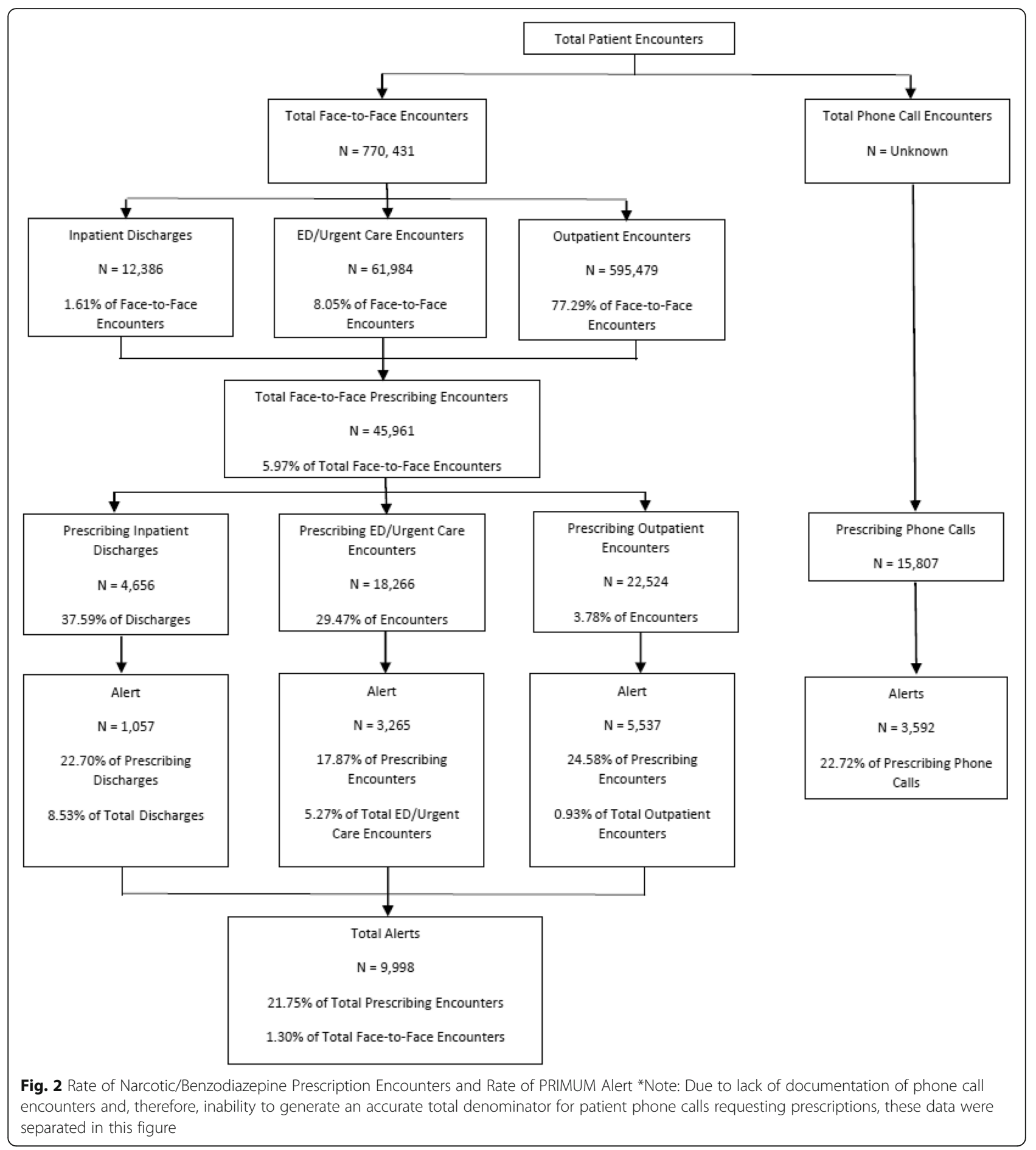

$10 \%$ of total encounters, yet $29.6 \%$ of prescribing encounters. While the majority of opioid and benzodiazepine prescriptions are written to patients 18-64 (73.80\%), $23.7 \%$ are written to older adults ( $\geq 65$ years of age), and $2.5 \%$ to children ( $\leq 17$ years of age). Opiates are prescribed more frequently $(73.2 \%)$ than benzodiazepines, and $3.8 \%$ of encounters resulted in co-prescribing opiates and benzodiazepines.
The most common trigger is a current prescription with $>50 \%$ remaining, present in $13.54 \%$ of prescribing encounters, while previous presentation for overdose is the least prevalent $(0.81 \%)$. The alert would have fired in $22.00 \%$ of prescribing encounters. While the majority of patients did not meet any criteria (78.00\%), $4.97 \%$ of prescribing encounters were with patients meeting multiple risk criteria. 


\section{Discussion}

Prescription opioid and benzodiazepine use has reached epidemic proportions in the United States. Through literature review and consensus building with a multidisciplinary team, we identified five objective criteria (See Final Triggers) that indicate high risk for misuse, abuse, and diversion of prescription opioids and benzodiazepines and built an alert system in the electronic medical record of a large healthcare system. We found that a significant number of patients meeting these criteria are being prescribed opioids or benzodiazepines, indicating risk for misuse, abuse, and diversion. However, the alert will fire in a small percentage of patient encounters, and thus should not be intrusive to prescribers' workflow.

We are not aware of any previous studies that have used this process to prospectively develop and test interventions in the EMR. However, there are examples in the literature of utilizing an intensive process of modeling clinical data "warehouses" for refining alerts related to medication orders [46, 47]. These previous authors utilized clinical data to model outcomes resulting from various thresholds set for medication alerts. The method we present in this paper is a novel, and another, approach to the development, testing, and implementation of clinical decision support in the EMR. The combination of expert panel and literature review coupled with "silent" phases to properly test and tune the triggers using "live" data is a novel approach that can be utilized in the development of future EMR-based interventions. These two "silent" alert phases were extremely useful, both for obtaining baseline data and to test the alert prior to launching this intervention. Similar testing of real clinical data in a non-clinical test environment has been utilized in other electronic medical record settings [48]. The data collected allowed us to choose triggers that did not cause the alert to fire too often, but successfully captured the at-risk population. This was important to minimize the potential for alert fatigue. These data were also helpful in obtaining support for deployment of this intervention within the healthcare system by being able to illustrate the problem, as well as provide evidence that the alert would be minimally obtrusive.

This intervention is currently being implemented in a single, although very large, healthcare system, which limits the available information about prescriptions or past medical history to encounters inside this system. Therefore, future interventions will aim to link to the state-wide prescription drug monitoring program to obtain a complete prescription history for each patient, as well as expand to other regional healthcare systems. In addition, we acknowledge that alerts do not exist in a vacuum and, while PRIMUM may not be that intrusive to prescribers, we are unable to determine the number of alerts a given prescriber might see for a given patient outside of the alert for PRIMUM, or the number of alerts seen during a day or clinical shift. Collaboration and coordination within a large healthcare system to address clinical decision support is needed. Future research will analyze the prescriber behavior related to the alert as well as the appropriateness of these triggers for subpopulations, such as cancer, chronic pain, or palliative care patients. The data on specific populations will also be used to develop targeted interventions to assist prescribers and patients once risk is identified.

\section{Conclusions}

Future initiatives in healthcare systems should utilize the capacity of their EMR to collect data prospectively to inform interventions. Given the complexity of a large healthcare system, it is important that EMR alerts are tested and tuned sufficiently to ensure a smooth rollout and that buy-in and support from all stakeholders is obtained early in the process. The utilization of the silent phases was a useful step that is translatable to other EMR systems.

\section{Acknowledgments \\ PRIMUM Group (in alphabetical order): Michael Beuhler, MD; Rebecca Boland; Michael J. Bosse, MD; Stephen Colucciello, MD; Emily Gerkin; Michael Gibbs, MD; Christopher Griggs, MD; Anthony Jacobson; Steven Jarrett, PharmD; Jan Losby, PhD; Monica Mowry, MSN; Michael Runyon, MD; Animita Saha, MD; Sharon Schiro, PhD; Bradley Watling, MD; Claire Wedgworth; Stephen Wyatt, DO \\ Funding \\ Financial Support: This work was supported in part by a cooperative agreement (CE14-004 Award Number CE002520) from the Centers for Disease Control and Prevention and by an internal grant from the Carolinas Trauma Network Research Center of Excellence. Disclaimer: The findings and conclusions in this report are those of the authors and do not necessarily represent the official position of the Centers for Disease Control and Prevention (CDC).}

\section{Availability of data and materials}

Data will not be shared at this time because it contains protected health information and we are currently analyzing the effectiveness of the alert.

\section{Authors' contributions}

RBS and JRH are the co-principal investigators of this study. RBS, DL, MKW, $J R H, M B, M J B, S C, M G, C G, S J, M M, M R, A S, B W$, and SW contributed to the conception of the study. RBS, DL, JRH, MB, MJB, SC, MG, CG, SJ, MM, MR, AS, $B W, S W, R B, A J$, and $C W$ contributed to the development of the intervention. EG, SS, MKW, RBS, and JRH completed the statistical analyses. All authors contributed to the writing of the manuscript.

\section{Competing interests \\ The authors declare that they have no competing interests.}

\section{Consent for publication}

Not applicable.

Ethics approval and consent to participate

This work was conducted following Carolinas HealthCare System Institutional Review Board review and approval (IRB \#12-14-04E) granted on 12/3/2014. The IRB waived the requirement for obtaining informed consent. 
Received: 3 March 2016 Accepted: 18 August 2016

\section{Published online: 22 August 2016}

\section{References}

1. Paulozzi LJ, Jones CM, Mack KA, Rudd RA. Vital signs: Overdoses of prescription opioid pain relievers-United States, 1999-2008. MMWR. 2011; 60(43):1487-92.

2. Jones CM, Mack KA, Paulozzi LJ. Pharmaceutical overdose deaths, United States, 2010. JAMA. 2013;309(7):657-9. doi:10.1001/jama.2013.272.

3. Centers for Disease Control and Prevention. Vital signs: overdoses of prescription opioid pain relievers-United States, 1999-2008. MMWR. 2011;60: 1487-92.

4. Bronson WD. The North Carolina Controlled Substances Reporting System: A valuable tool for combating prescription drug misuse. NCMJ. 2013;74(3):249-53.

5. Ford MD. Unintentional poisoning in North Carolina: An emerging public health problem. NCMJ. 2010;71(6):542-6.

6. Executive Office of the President of the United States. Epidemic: Responding to America's Prescription Drug Abuse Crisis 2011. Available at https://www.whitehouse.gov/sites/default/files/ondcp/policy-andresearch/rx_abuse_plan.pdf. Accessed June 2015.

7. US Department of Health and Human Services. HHS takes strong steps to address opioid-drug related overdose, death and dependence. 2015. Available at http://www.hhs.gov/about/news/2015/03/26/hhs-takes-strongsteps-to-address-opioid-drug-related-overdose-death-and-dependence.html. Accessed Mar 2015.

8. US Drug Enforcement Administration. Drug Scheduling. 2016. http://www. dea.gov/druginfo/ds.shtml. Accessed Feb 2016.

9. Volkow ND, Mclellan TA, Cotto JH. Characteristics of opioid prescriptions in 2009. JAMA. 2011;305(13):1299-300. doi:10.1001/jama.2011.401.

10. Blumenschein $\mathrm{K}$, Fink JL, Freeman PR, Kirsh KL, Steinke DT, Talbert J. Independent evaluation of the impact and effectiveness of the Kentucky All Schedule Prescription Electronic Reporting System (KASPER): Institute for Phamaceutical Outcomes and Policy 2010. Available at http://www.chfs.ky. gov/NR/rdonlyres/24493B2E-B1A1-4399-89AD-1625953BAD43/0/ KASPEREvaluationFinalReport10152010.pdf. Accessed June 2015.

11. Dhalla IA, Mamdani MM, Gomes T, Juurlink DN. Clustering of opioid prescribing and opioid-related mortality among family physicians in Ontario. Can Fam Physician. 2011;57(3):e92-6.

12. Swedlow A, Ireland J, Johnson G. Prescribing patterns of schedule II opioids in California workers' compensation: California Workers' Compensation Institute 2011. Available at www.cwci.org/document.php?file=1438.pdf. Accessed June 2015

13. Singh $H$, Spitzmueller C, Petersen NJ, Sawhney MK, Sittig DF. Information overload and missed test results in electronic health record-based settings. JAMA Internal Med. 2013;173(8):702-3. doi:10.1001/2013.jamainternmed.61.

14. Holden RJ. Cognitive performance-altering effects of electronic medical records: an application of the human factors paradigm for patient safety. Cogn Tech Work. 2011;13:11-29.

15. Hunt DL, Haynes B, Hanna SE, Smith K. Effects of computer-based clinical decision support systems on physician performance and patient outcomes: A systematic review. JAMA. 1998;280(15):1339-46. doi:10.1001/jama.280.15.1339.

16. Shea S, Dumouchel W, Bahamonde L. A meta-analysis of 16 randomized controlled trials to evaluate computer-based clinical reminder systems for preventive care in the ambulatory setting. J Am Med Inform Assoc. 1996;3(6):339-409.

17. Smith DH, Perrin N, Feldstein A, Yang X, Kuang D, Simon SR, et al. The impact of prescribing safety alerts for elderly persons in an electronic medical record: An interrupted time series evaluation. Arch Intern Med. 2006;166:1098-104. doi:10.1001/archinte.166.10.1098.

18. Pearson SA, Moxey A, Robertson J, Hains I, Williamson M, Reeve J, et al. Do computerised clinical decision support systems for prescribing change practice? A systematic review of the literature (1990-2007). BMC Health Serv Res. 2009:9:154. doi:10.1186/1472-6963-9-154.

19. McCoy AB, Thomas EJ, Krousel-Wood M, Sittig DF. Clinical decision support alert appropriateness: A review and proposal for improvement. Ochsner J. 2014;14:195-202

20. Loo TS, Davis RB, Lipsitz LA, Irish J, Bates CK, Agarwal K, et al. Electronic medical record reminders and panel management to improve primary care of elderly patients. Arch Intern Med. 2011;171(17):1552-8. doi:10.1001/archinternmed.2011.394
21. Kucher N, Koo S, Quiroz R, Cooper JM, Paterno MD, Soukonnikov B, et al. Electronic alerts to prevent venous thromboembolism among hospitalized patients. N Engl J Med. 2005;352(10):969-77. doi:10.1056/NEJMoa041533.

22. Perna G. Clinical alerts that cried wolf. As clinical alerts pose physician workflow problems, healthcare IT leaders look for answers. Healthc Inform. 2012;29(4):18-20.

23. Feldstein AC, Smith DH, Robertson NR, Kovach CA, Soumerai SB, Simon SR, et al. Decision Support System Design and Implementation for Outpatient Prescribing: The Safety in Prescribing Study. In: Henriksen K, Battles JB, Marks ES, editors. Advances in Patient Safety: From Research to Implementation. Rockville: Agency for Healthcare Research and Quality; 2005. p. 35-50.

24. Shah NR, Seger AC, Seger DL, Fiskio JM, Kuperman GJ, Blumenfeld B, et al. Improving acceptance of computerized prescribing alerts in ambulatory care. J Am Med Inform Assoc. 2006;13(1):5-11. doi:10.1197/jamia.M1868.

25. van der Sijs H, Aarts J, Vulto A, Berg M. Overriding of drug safety alerts in computerized physician order entry. J Am Med Inform Assoc. 2006;13(2): 138-47. doi:10.1197/jamia.M1809.

26. Ulrich B. Alarm fatigue: A growing problem. Nephrol Nurs J. 2013;40(4):293.

27. Trafton J, Martins S, Michel M, Wang D, Tu S, Clark D, et al. Designing an automated clinical decision support system to match clinical practice guidelines for opioid therapy for chronic pain. Implement Sci. 2010;5(26):1-11.

28. Trafton J, Martins S, Michel M, Lewis E, Wang D, Combs A, et al. Evaluation of the acceptability and usability of a decision support system to encourage safe and effective use of opioid therapy for chronic, noncancer pain by primary care providers. Pain Med. 2010;11(4):575-85.

29. Cerner. Company Fact Sheet. 2015. http://www.cerner.com/uploadedFiles/ Content/About_Cerner/Fact\%20Sheet_2016Q1.pdf. Accessed June 32016.

30. Dormuth CR, Miller TA, Huang A, Mamdani MM, Juurlink DN. Effect of a centralized prescription network on inappropriate prescriptions for opoid analgesics and benzodiazepines. CMAJ. 2012;184(16):E852-6. doi:10.1503/cmaj.121495.

31. Yang Z, Wilsey B, Bohm M, Weyrich M, Roy K, Ritley D, et al. Defining risk of prescription opioid overdose: pharmacy shopping and overlapping prescriptions among long-term opioid users in medicaid. J Pain. 2015;16(5):445-53. doi:10.1016/j.jpain.2015.01.475.

32. Mack KA, Zhang $K$, Paulozzi $L$, Jones $C$. Prescription practices involving opioid analgesics among Americans with Medicaid, 2010. J Health Care Poor Underserved. 2015:26(1):182-98. doi:10.1353/hpu.2015.0009.

33. Grover CA, Garmel GM. How Do Emergency Physicians Interpret Prescription Narcotic History When Assessing Patients Presenting to the Emergency Department with Pain? Perm J. 2012;16(4):32-6. doi:10.7812/TPP/12-038.

34. Paulozzi し. Prescription drug overdoses: a review. J Safety Res. 2012;43(4):283-9. doi:10.1016/j.jsr.2012.08.009.

35. Paulozzi $\amalg$, Kilbourne EM, Shah NG, Nolte KB, Desai HA, Landen MG, et al. A history of being prescribed controlled substances and risk of drug overdose death. Pain Med. 2012;13:87-95. doi:10.1111/j.1526-4637.2011.0160.x.

36. Colburn JL, Jasinski DR, Rastegar DA. Long-term opioid therapy, aberrant beaviors, and substance misuse: Comparison of patients treated by resident and attending physicians in a general medical clinic. J Opioid Manag. 2012;8(3):153-60. doi:10.5005/jom.2012.0111.

37. Johnson EM, Lanier WA, Merrill RM, Crook J, Porucznik CA, Rolfs RT, et al. Unintentional prescription opioid-related overdose deaths: description of decedents by next of kin or best contact, Utah, 2008-2009. J Gen Intern Med. 2012;28(4):522-9. doi:10.1007/s11606-012-2225-z.

38. Jones CM, Paulozzi LJ, Mack KA. Alcohol Involvement in Opioid Pain Reliever and Benzodiazepine Drug Abuse-Related Emergency Department Visits and Drug-Related Deaths-United States, 2010. MMWR. 2014;63(40):881-5.

39. Sehgal N, Manchikanti L, Smith HS. Prescription Opioid Abuse in Chronic Pain: A Review of Opioid Abuse Predictors and Strategies to Curb Opioid Abuse. Pain Physician. 2012;15:ES67-92.

40. Russ AL, Zillich AJ, McManus MS, Doebbeling BN, Saleem JJ. A human factors investigation of medication alerts: barriers to prescriber decisionmaking and clinical workflow. AMIA Annu Symp Proc. 2009;2009:548-52.

41. Kelley J, Kraft-Todd G, Schapira L, Kossowsky J, Riess H. The influence of the patient-clinician relationship on healthcare outcomes: A systematic review and meta-analysis of randomized controlled trials. PLoS One. 2014;9(4):e92407.

42. Idemoto L, Wiliams B, Ching J, Blackmore C. Implementation of a custom alert to prevent medication-timing errors associated with computerized prescriber order entry. Am J Health Syst Pharm. 2015;72(17):1481-8. 
43. Stewart M, Mcwhinney I, Buck C. The doctor/patient relationship and its effect upon outcome. J R Coll Gen Pract. 1979;29:77-82.

44. Di Blasi Z, Harkness E, Ernst E, Georgiu A, Kleijnen J. Influence of context effects on health outcomes: A systematic review. Lancet. 2001;357:757-62.

45. Ong L, de Haes J, Hoos A, Lammes F. Doctor-patient communication: A review of the literature. Soc Sci Med. 1995;40:903-18.

46. Boussadi A, Caruba T, Zapletal E, Sabatier B, Durieux P, Degoulet P. A clinical data warehouse-based process for refining medication orders alerts. J Am Med Inform Assoc. 2012;19(5):782-5.

47. Oppenheim M, Mintz R, Boyer A, Frayer W. Design of a clinical alert system to facilitate development, testing, maintenance, and user-specific notification. Proc AMIA Symp. 2000;2000:630-4.

48. Russ AL, Chen S, Melton BL, Saleem JJ, Weiner M, Spina JR, et al. Design and evaluation of an electronic override mechanism for medication alerts to facilitate communication between prescribers and pharmacists. Ann Pharmacother. 2015;49(7):761-9.

49. Bonar EE, Ilgen MA, Walton M, Bohnert AS. Associations among pain, nonmedical prescription opioid use, and drug overdose history. Am J Addict. 2014;23(1):41-7. doi:10.1111/j.1521-0391.2013.12055.x.

50. Zedler B, Xie L, Wang L, Joyce A, Vick C, Kariburyo F, et al. Risk Factors for Serious Prescription Opioid-Related Toxicity or Overdose among Veterans Health Administration Patients. Pain Med. 2014;15:1911-29. doi:10.1111/pme.12480.

51. Jones C, Paulozzi LJ, Mack KA. Sources of prescription opioid pain relievers by frequency of past-year nonmedical use: United States, 2008-2011. JAMA Internal Med. 2014;174(5):802-3. doi:10.1001/jamainternmed.2013.1809.

52. Weiner SG, Griggs CA, Langlois BK, Mitchell PM, Nelson KP, Friedman FD, et al. Characteristics of emergency department "doctor shoppers". J Emerg Med. 2015;48(4):424-31. doi:10.1016/j.jemermed.2014.11.008. e1.

53. Hall AJ, Logan JE, Toblin RL, Kaplan JA, Kraner JC, Bixler D, et al. Patterns of abuse among unintentional pharmaceutical overdose fatalities. JAMA. 2008;300(22):2613-20. doi:10.1001/jama.2008.802.

54. Lanier WA, Johnson EM, Rolfs RT, Friedrichs MD, Grey TC. Risk factors for prescription opioid-related death, Utah, 2008-2009. Pain Med. 2012;13:1580-9. doi:10.1111/j.1526-4637.2012.01518.x.

55. Hasegawa K, Brown DF, Tsugawa Y, Camargo Jr CA. Epidemiology of emergency department visits for opioid overdose: a population-based study. Mayo Clin Proc. 2014;89(4):462-71. doi:10.1016/j.mayocp.2013.12.008.

56. Peirce GL, Smith MJ, Abate MA, Halverson J. Doctor and pharmacy shopping for controlled substances. Med Care. 2012;50:494-500. doi:10.1097/MLR.0b013e31824ebd81.

57. Stogner JM, Sanders A, Miller BL. Deception for drugs: self-reported "doctor shopping" among young adults. J Am Board Fam Med. 2014;27(5):583-93. doi:10.3122/jabfm.2014.05.140107.

58. Silva K, Schrager SM, Kecojevic A, Lankenau SE. Factors associated with history of non-fatal overdose among young nonmedical users of prescription drugs. Drug Alcohol Depend. 2013;128(1-2):104-10. doi:10.1016/j.drugalcdep.2012.08.014.

59. Webster LR, Webster RM. Predicting aberrant behaviors in opioid-treated patients: Preliminary validation of the opioid risk tool. Pain Med. 2005;6(6): 432-42. doi:10.1111/j.1526-4637.2005.00072.x.

60. Grover CA, Elder JW, Close RJ, Curry SM. How Frequently are "Classic" Drug-Seeking Behaviors Used by Drug-Seeking Patients in the Emergency Department? West J Emerg Med. 2012;13(5):416-21. doi:10.5811/westjem.2012.4.11600.

61. Toblin RL, Paulozzi LJ, Logan JE, Hall AJ, Kaplan JA. Mental illness and psychotropic drug use among prescription drug overdose deaths: a medical examiner chart review. J Clin Psychiatry. 2010;71(4):491-6. doi:10.4088/JCP.09m05567blu.

62. Beaudoin FL, Straube S, Lopez J, Mello MJ, Baird J. Prescription opioid misuse among ED patients discharged with opioids. Am J Emerg Med. 2014;32(6):580-5. doi:10.1016/j.ajem.2014.02.030.

63. Katz C, El-Gabalawy R, Keyes KM, Martins SS, Sareen J. Risk factors for incident nonmedical prescription opioid use and abuse and dependence: results from a longitudinal nationally representative sample. Drug Alcohol Depend. 2013;132(1-2):107-13. doi:10.1016/j.drugalcdep.2013.01.010.

64. Sundquist J, Ohlsson H, Sundquist K, Kendler KS. Attention-deficit/hyperactivity disorder and risk for drug use disorder: a population-based follow-up and corelative study. Psychol Med. 2015;45(5):977-83. doi:10.1017/S0033291714001986.

65. Morris BJ, Zumsteg JW, Archer KR, Cash B, Mir HR. Narcotic Use and Postoperative Doctor Shopping in the Orthopaedic Trauma Population. J Bone Joint Surg Am. 2014:96(15):1257-62. doi:10.2106/JBJS.M.01114.
66. Bohnert ASB, Valenstein M, Bair MJ, Ganoczy D, McCarthy JF, Ilgen MA, et al. Association Between Opioid Prescribing Patterns and Opioid OverdoseRelated Deaths. JAMA. 2011;305(13):1315-21. doi:10.1001/jama.2011.370.

67. Dunn KM, Saunders KW, Rutter CM, Banta-Green CJ, Merrill JO, Sullivan MD, et al. Opioid Prescriptions for Chronic Pain and Overdose: A Cohort Study. Ann Intern Med. 2010;152:85-92. doi:10.7326/0003-4819-152-2-201001190-00006.

68. Zechnick AD, Hedges JR. Community-wide emergency department visits by patients suspected of drug-seeking behavior. Acad Emerg Med. 1996;3(4): 312-7. doi:10.1111/j.1553-2712.1996.tb03443.x.

\section{Submit your next manuscript to BioMed Central and we will help you at every step:}

- We accept pre-submission inquiries

- Our selector tool helps you to find the most relevant journal

- We provide round the clock customer support

- Convenient online submission

- Thorough peer review

- Inclusion in PubMed and all major indexing services

- Maximum visibility for your research

Submit your manuscript at www.biomedcentral.com/submit
C Biomed Central 